
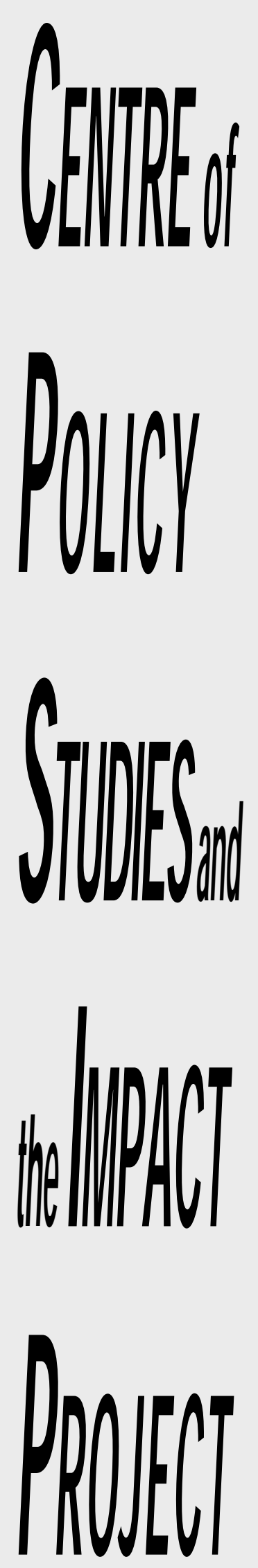

Eleventh Floor

Menzies Building

PO Box 11E, Monash University

Wellington Road

CLAYTON Vic 3800 AUSTRALIA

Telephone:

(03) 9905 2398, (03) 99055112

Fax:

(03) 99052426

e-mail

web site from overseas: 61399055112 or 61399052398

\section{6}

impact@buseco.monash.edu.au http://www.monash.edu.au/policy/

\title{
MEASURING CONTRIBUTIONS TO THE AUSTRALIAN ECONOMY: THE BENEFITS OF A FAST-GROWING MOTOR VEHICLE AND PARTS INDUSTRY
}

\author{
by \\ Peter B. DIXON \\ and \\ Maureen T. RIMMER \\ Centre of Policy Studies, Monash University
}

General Paper No. G-138, May 2003 quantitative analysis of issues relevant to Australian economic policy. 



\begin{abstract}
The contribution of an industry to the economy is often measured by an input-output calculation showing labour used directly in the industry and indirectly via the production of intermediate inputs for the industry. This paper demonstrates an alternative approach based on simulations with a dynamic computable general equilibrium model. Rather than measuring contribution in terms of resources used, we look at the potential contribution of an industry in terms of the effect on economic welfare of improved performance. We apply our methodology to the Australian motor vehicle industry by simulating the impact that this industry could make if it were to achieve higher productivity growth, higher export growth and the production of cars of greater appeal to Australian consumers.
\end{abstract}

JEL classifications: $C 67$ and C68

Key words: industry contribution, dynamic CGE analysis, input-output analysis, motor vehicle industry. 
1. Introduction

\section{Contents}

2. Simulation question: the contribution of a faster growing MV\&P industry

3. Key assumptions 3

3.1. Labour market 3

3.2. Public expenditure and taxes 4

3.3. Rates of return on capital 4 3.4. Production technologies, household preferences and
import/domestic twists

4. Improved multi-factor-productivity growth in the MV\&P industry (simulation 1) 6

4.1. Short-run macro results 7

4.2. Long-run macro results 9

5. Increased attractiveness in Australia of domestic MV\&P products relative to imported MV\&P products (simulation 2) 10

$\begin{array}{ll}\text { 6. Increased MV\&P exports (simulation 3) } & 10\end{array}$

7. A strongly growing MV\&P industry: combined shocks (simulation 4) 12

7.1. Macro results 12

7.2. Results for the MV\&P industry $\quad 13$

$\begin{array}{ll}\text { 7.3. Results for other industries } & 14\end{array}$

$\begin{array}{ll}\text { 8. Concluding remarks } & 15\end{array}$

$\begin{array}{ll}\text { References } & 17\end{array}$

Table and Charts

Table 2.1. MONASH business-as-usual forecasts: Average annual percentage growth rates for Australia from 2001 to 2006

Chart 4.1. Selected macro variables: increased MV\&P productivity 6

Chart 5.1. Selected macro variables: increased MV\&P attractiveness 11

Chart 6.1. Selected macro variables: increased MV\&P exports 11

$\begin{array}{ll}\text { Chart 7.1. Selected macro variables: combined MV\&P shocks } & 13\end{array}$

$\begin{array}{ll}\text { Chart 7.2. MV\&P variables: combined MV\&P shocks } & 14\end{array}$

Chart 7.3. Outputs of main winners and losers: combined MV\&P shocks $\quad 15$ 


\title{
Measuring contributions to the Australian economy: the benefits of a fast-growing motor vehicle and parts industry
}

\author{
by \\ Peter B. Dixon and Maureen T. Rimmer*
}

\section{Introduction}

In our role as consultants, we often respond to tenders from industry associations and large firms seeking quantification of the contribution of their industry to a national or regional economy. Normally the potential client has some form of input-output computation in mind and is looking for a multiplier that will inflate the apparent level of employment and output associated with the industry. ${ }^{1}$ The usual objective envisaged for the analysis is to impress governments during negotiations for assistance or to impress the public in a general awareness-raising campaign.

In effect, what the client is asking for is an estimate of the implications of eliminating the industry of interest from the regional or national economy. Implicitly, the client wants this estimate made under the assumption that resources used by the industry, directly and indirectly, would be lost to the economy (through unemployment or emigration) if the industry were closed down. The problem is that both the question and assumption are unrealistic. There is no real expectation by the client that the industry will close down, and the assumption that all the people who work in the industry and the people who supply inputs to the industry would emigrate or be unemployed without the industry is unsupportable. On the contrary, clients are usually optimistic about their industry's future, and even if their industry were to close down, at least part of the released resources would flow to other industries in the regional or national economy.

To us, the contribution that an industry can make to the economy is not measured by employment in the industry and in its suppliers. Employment is an indication of what the industry takes out of the economy. Apart from short-run adjustment issues, the decision by an industry to employ more people is a decision to impose a cost on the economy which must be compensated by increased output.

\footnotetext{
* Centre of Policy Studies, Monash University. We thank John Madden for valuable suggestions and two referees for excellent comments on an earlier draft.
} 
In the long run, an industry's contribution to the economy should be measured by improvements in the industry's ability to make productive use of the economy's resources. In other words, the main contribution that an industry can make is to improve its own productivity.

To estimate an industry's contribution to the economy, we need a technique for answering realistic questions concerning the implications of changes in the industry's performance under realistic assumptions concerning the opportunity costs of the industry's resources. In our view, the best technique currently available is computable general equilibrium (CGE) modelling. Unlike input-output models, CGE models can provide answers to a wide variety of questions on the effects of changes in production methods (technology) and other aspects of industry performance under plausible assumptions on inter-industry factor movements.

In this paper we illustrate the application of CGE modelling to the contribution issue by using MONASH simulations in an analysis of the motor vehicle and parts (MV\&P) industry. ${ }^{2}$ Section 2 sets out the simulation question. Section 3 lists our underlying assumptions. Sections 4 to 7 report results and section 8 contains concluding remarks.

No knowledge of MONASH will be required to understand our results. They are justified in sections 4 to 7 through back-of-the-envelope calculations involving familiar economic mechanisms.

\section{Simulation question: the contribution of a faster growing MV\&P industry}

Table 2.1 contains forecasts for the Australian economy generated by MONASH under business-as-usual assumptions. These forecasts show average annual GDP and employment growth over the next five years of 2.9 and 1.3 per cent. However output and employment growth in the MV\&P industry average only 1.0 and -0.9 per cent. Output growth in MV\&P is restricted by relatively rapid growth in MV\&P imports allowing the import share of the domestic market for MV\&P products to increase from 42 per cent in 2001 to 46 per cent in 2006. Employment opportunities in the MV\&P industry are restricted not only by slow growth in output but also by productivity growth.

\footnotetext{
${ }^{1}$ Prominent among the Australian studies on input-output multipliers and the contributions of industries to the economy are Jensen and West (1986, Chapter 7) and Groenewold et al. (1987 and 1993).

2 MONASH is a detailed dynamic CGE model of Australia with both national and multi-regional versions. Here we use the national version described in Dixon and Rimmer (2002). Descriptions and applications of the multi-regional version can be found in Naqvi and Peter (1996) and Adams et al. (2000).
} 
Table 2.1. MONASH business-as-usual forecasts:

Average annual percentage growth rates for Australia from 2001 to 2006

Real GDP

Aggregate employment

Output of Motor vehicles and parts (MV\&P)

Employment in the MV\&P industry

Imports of MV\&P products

\section{9}

1.3

1.0

$-0.9$

4.7

How could the MV\&P industry make a contribution to the Australian economy? Would it make a contribution by exceeding its business-as-usual forecast rate of growth? Here we use MONASH to quantify the benefits to Australia of an MV\&P industry that grows by about 20 per cent over the next 5 years rather than 5 per cent (3.6 per cent per annum rather than 1.0 per cent).

We see three channels through which the MV\&P industry could improve on its growth performance over that in our business-as-usual forecasts:

(i) by increasing its rate of productivity growth (simulation 1, reported in section 4);

(ii) by increasing the attractiveness of its products to domestic users thereby increasing its market share in Australia (simulation 2, reported in section 5); and

(iii) by obtaining increased export allocations from parent companies in world markets for cars and parts (simulation 3, reported in section 6).

For each channel, we conduct a MONASH simulation showing the implications of an improved performance that lifts average annual output growth over the next 5 years by about 0.9 percentage points. Then in section 7 we allow all three improvements to operate simultaneously. With extra growth of about 0.9 percentage points from each improvement, overall growth in the industry's output is raised from the business-as-usual forecast of 1.0 per cent a year to about 3.6 per cent.

\section{Key assumptions}

\subsection{Labour market}

We assume that workers are concerned with the real after-tax wage rate, that is, the wage rate less income taxes, deflated by the CPI. If the labour market weakens, then we assume that the real after-tax wage rate declines in response to reduced bargaining power by workers. More technically, we assume that the deviation in the economy-wide average real after-tax wage rate from its basecase forecast level increases in proportion to the deviation in aggregate employment from its basecase forecast level. The coefficient of proportionality is chosen so that the aggregate 
employment effects of a shock to the economy are largely eliminated after 5 years. In other words, after about 5 years the costs or benefits of a shock such as additional productivity improvements in the MV\&P industry (additional to those in the basecase forecast) are realized almost entirely as a decrease or increase in the average real after-tax wage rate. This labour market assumption is consistent with conventional macro-economic modelling in which the NAIRU is exogenous.

\subsection{Public expenditure and taxes}

We assume that the shocks considered in this paper to the MV\&P industry make no difference to the path of real public consumption and that there are no adjustments in tax rates to compensate for changes in tax revenue and outlays associated with changes in the level of economic activity. As can be seen in section 7, in combination, our simulations show an increase in economic activity which generates movements in the government's budget towards surplus.

\subsection{Rates of return on capital}

In simulations of the effects of changes in policy and other exogenous variables, MONASH allows for short-run divergences in after-tax rates of return on industry capital from their levels in the basecase forecasts. Short-run increases/decreases in rates of return cause increases/decreases in investment and capital, thereby gradually eroding the initial divergences in after-tax rates of return.

\subsection{Production technologies, household preferences and import/domestic twists}

In MONASH, industry outputs are functions of inputs of labour, capital, land and commodities, with each commodity input being a CES combination of the domestic and the imported variety. Similarly, household utility is a function of consumption of different commodities with each being a CES combination of the domestic and the imported variety. Associated with each flow of primary factors and commodities, MONASH contains a variable allowing for input-saving or using changes in technology or preferences. For each commodity, MONASH also contains a twist variable that allows for non-price-induced changes in the domestic/import composition of purchases by industries and households without causing changes in their overall use of the commodity. In the simulations described in sections 4 to 7 , we assume that all technology and twist variables have the same values as in the basecase forecasts with following exceptions.

In section 4, we assume that the MV\&P industry achieves additional multi-factorproductivity gains in each of the five years 2002 to 2006 of 0.64 per cent, making a total gain by 
2006 of 3.2 per cent. This means that the MV\&P industry is able to produce any given level of output in 2006 with 3.2 per cent less of all inputs than were needed in the basecase forecasts. The number 3.2 was chosen, after some experimentation, because it gave the MV\&P industry additional annual output growth for the next five years of 0.9 per cent, accumulating to additional output in 2006 of about 5 per cent.

In section 5, where we impose a twist in Australian preferences away from imports sufficient to give additional MV\&P output in 2006 of 5 per cent, we assume additional multifactor-productivity gains in each of the five years 2002 to 2006 of 0.05 per cent. This makes a total gain by 2006 of 0.25 per cent. In arriving at this multi-factor-productivity number, we assumed that extra MV\&P output of 5 per cent is accompanied by an expansion in the flow of Australian-made parts to the MV\&P industry of 5 per cent. Because the production of parts is subject to economies of scale, an increase in this flow will decrease the cost of parts to the MV\&P industry. A reasonable assumption is that the ratio of marginal to average cost in Australia's production of parts for the MV\&P industry is 0.75 . Thus, a 5 per cent increase in the flow of Australian-made parts to the MV\&P industry generates a decrease in the cost per unit of flow of 1.25 per cent $\left(=5^{*} 0.25\right)$. From the point of view of the whole MV\&P industry, inputs of Australian-produced parts are 19.9 per cent of total costs $(\$ 2.963$ billion out of $\$ 14.897$ billion of total inputs, ABS input/output tables for 1996/97). Thus, a 1.25 per cent decrease in the cost per unit of parts input is equivalent to an increase in multi-factor productivity of 0.25 per cent $(=1.25 * 0.199)$.

Unlike the simulations in sections 4 and 5 where the shocks are phased in over 5 years, in section 6 the shock is imposed in a single year, 2002. We assume that MV\&P parent companies allow their Australian subsidiaries to increase their exports in 2002 sufficiently to generate an immediate increase in output of 5 per cent. The extra exports are achieved by additional production shifts without requiring significant increases in inputs of capital or of non-production workers. Specifically, we assume that the 5 per cent increase in MV\&P output requires a 2.5 per cent increase in labour input and no increase in capital input. With capital and labour inputs each representing about 12.5 per cent of MV\&P costs, our assumptions imply an increase in multifactor productivity of 0.9 per cent $[=0.125 *(5-2.5)+0.125 *(5-0)]$. As for the simulation in section 5, in section 6 we assume additional MV\&P output of 5 per cent is accompanied by a further multi-factor-productivity increase of 0.25 per cent resulting from economies of scale associated with a 5 per cent expansion in the flow of Australian-made parts to the MV\&P 
industry. Thus, in total, the improvement in multi-factor productivity in the MV\&P industry assumed in section 6 is about 1.15 per cent, occurring in 2002 .

In section 7 we combine all of the shocks applied in sections 4, 5 and 6 . Thus we assume an increase in multi-factor productivity in the MV\&P industry of 1.84 per cent in $2002(=0.64+$ $0.05+1.15)$ rising to 4.6 per cent in $2006(=3.2+0.25+1.15)$.

\section{Improved multi-factor-productivity growth in the MV\&P industry (simulation 1)}

Chart 4.1 shows MONASH results for this simulation as percentage deviations from basecase forecasts. For example, the employment line in Chart 4.1 shows for 2002 that 0.64 per cent extra multi-factor-productivity growth in the MV\&P industry causes an increase in aggregate employment of 0.018 per cent, implying that employment in that year would be about 1,800 jobs greater with the additional productivity growth than without it.

\section{Chart 4.1. Selected macro variables: increased MV\&P productivity (\% deviations from basecase forecasts)}

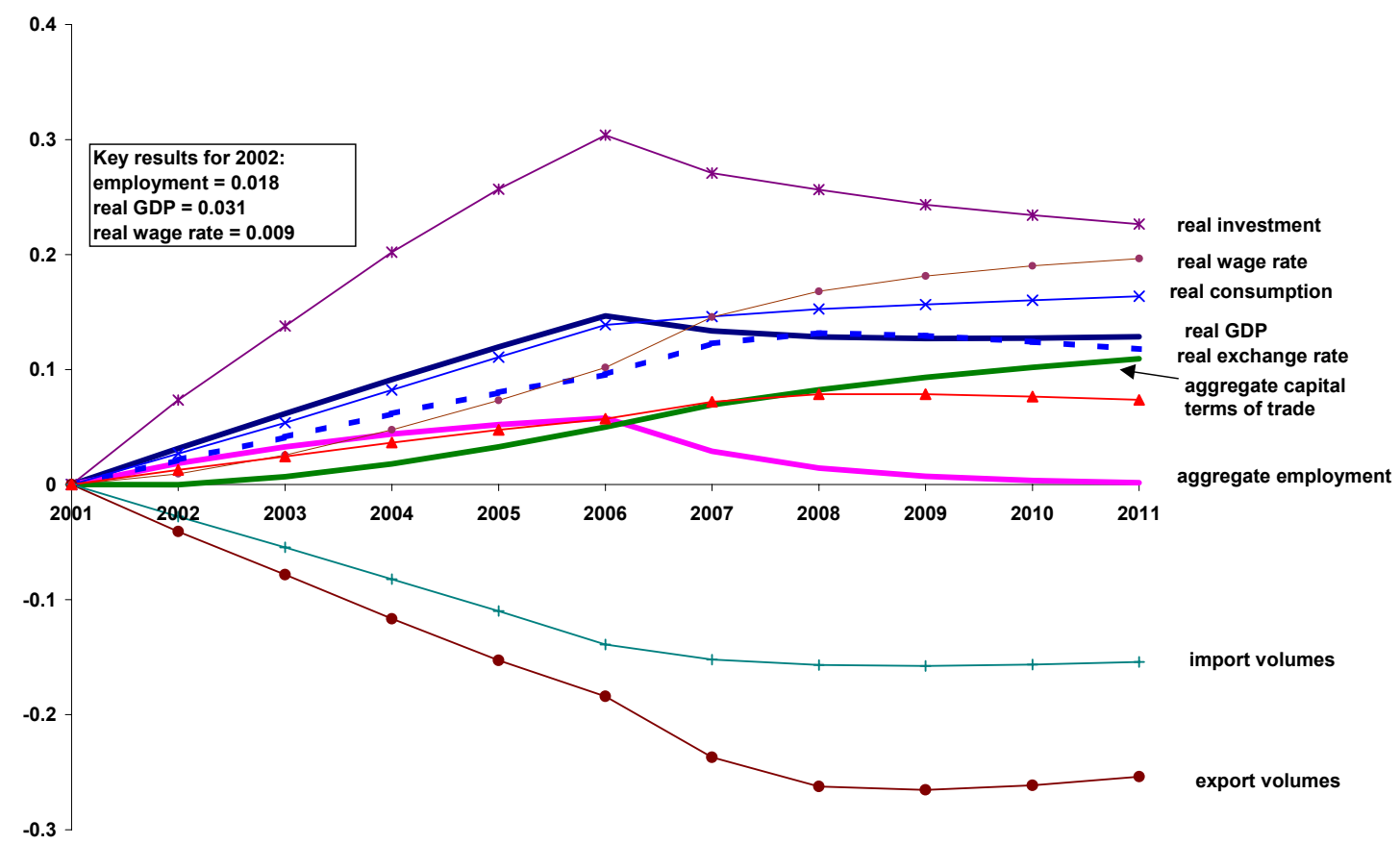




\subsection{Short-run macro results}

A useful framework for understanding the short-run increase in employment shown in Chart 4.1 is the following:

$$
\ell=k+\theta^{*}(p-w+a) / S_{k}
$$

where

$\ell$ is the percentage deviation in aggregate employment caused by the extra MV\&P productivity growth;

$\mathrm{k}$ is the percentage deviation in aggregate capital;

$\mathrm{S}_{\mathrm{k}}$ is the capital share in GDP;

$\theta$ is the elasticity of substitution between capital and labour;

$\mathrm{p}$ is the percentage deviation in the price deflator for GDP;

$\mathrm{W}$ is the percentage deviation in the average wage rate; and

a is the percentage deviation in economy-wide factor productivity.

Equation (4.1) can be derived from a profit maximising specification of the form:

choose L (employment) and Y (output) to maximize

$$
\mathrm{PY}-\mathrm{WL} \text { subject to } \mathrm{Y}=\mathrm{A} * \mathrm{CES}(\mathrm{K}, \mathrm{L})
$$

where

$\mathrm{P}, \mathrm{W}$ and $\mathrm{K}$ are the product price, the wage rate and the capital stock, all treated as exogenous variables in this maximisation problem; and

$\mathrm{A}$ is an exogenous technology variable.

Specifications such as (4.2) are representative of the behavioural assumptions built into MONASH.

In MONASH, $\mathrm{S}_{\mathrm{k}}$ is approximately 0.3 and $\theta$ is set at 0.5 for all industries. In the short run, extra productivity growth in the MV\&P industry does not affect the economy's capital stock. Hence, $\mathrm{k}=0$. A technological improvement of 0.64 per cent in the MV\&P industry translates to a 0.019 per cent improvement for the economy as a whole ${ }^{3}$. Under the wage assumption outlined in subsection 3.1, the short-run movement in prices relative to wages is muted. However, as can be seen from Chart 4.1, real wages rise in the first year. Using results not shown in the chart we find that the increase in the wage rate (reflecting strengthening of the labour market) is about

\footnotetext{
${ }^{3}$ In the MONASH database inputs to the MV\&P industry are about 3 per cent of GDP.
} 
0.012 per cent relative to the change in the price deflator for GDP, that is $\mathrm{p}-\mathrm{w}$ is -0.012 . Putting all these numbers into the RHS of (4.1) gives $\ell=0.012$.

On investigation we found that the discrepancy between this back-of-the-envelope calculation $(\ell=0.012)$ and the MONASH result $(\ell=0.018)$ was due to changes in the expenditure composition of GDP. As will be explained shortly, the MONASH simulation showed increases in investment (a labour intensive component of GDP) and decreases in exports (a capital intensive component of GDP). This caused the increase in employment to be greater than can be explained by a single-sector back-of-the-envelope calculation. To check this explanation, we ran an alternative simulation in which the productivity shock to the MV\&P sector was not allowed to affect investment. The alternative simulation produced an employment increase of almost exactly the level suggested by our back-of-the-envelope calculation.

With an improvement in economy-wide technology, and a gain in labour input and no change in capital input, there must be an increase in real GDP. This can be approximated from the equation ${ }^{4}$ :

$$
\mathrm{y}=\mathrm{a}+\mathrm{S}_{\mathrm{k}} \mathrm{k}+\mathrm{S}_{\ell} \ell
$$

where

$\mathrm{y}$ is the percentage deviation in real GDP;

$\mathrm{S}_{\ell}$ is the labour share in real GDP (approximately 0.7); and

$\mathrm{a}, \mathrm{S}_{\mathrm{k}}, \mathrm{k}$ and $\ell$ are as defined earlier.

With $\mathrm{a}=0.019, \mathrm{k}=0, \ell=0.018, \mathrm{~S}_{\mathrm{k}}=0.3$ and $\mathrm{S}_{\ell}=0.7$, equation (4.3) gives $\mathrm{y}=0.032$. This is close to the deviation result for GDP in 2002 shown in Chart 4.1.

Apart from increases in employment and GDP, other short-run macroeconomic effects of additional multi-factor-productivity growth in the MV\&P industry that can be seen in Chart 4.1 are: a relatively sharp increase in economy-wide investment; a decrease in exports relative to imports facilitated by real appreciation; an increase in the average real wage rate; an increase in the terms of trade; and an increase in consumption ${ }^{5}$ associated with the increases in employment and the terms of trade.

The relatively sharp increase in investment reflects tighter capacity constraints throughout the economy associated with increases in output and employment. More technically,

\footnotetext{
${ }^{4}$ Equation (4.3) follows from the profit maximisation problem (4.2).
} 
with the short-run percentage increase in employment (0.018 per cent) exceeding the short-run percentage increase in capital ( 0.0 per cent), there is a decrease in the $\mathrm{K} / \mathrm{L}$ ratio. This causes increases in rental rates on capital and rates of return, and consequently in investment.

The increase in investment strengthens the exchange rate facilitating a deterioration in the balance of trade. This is achieved through a reduction in exports. An upside of the export decrease is an increase in the terms of trade. Despite appreciation and an increase in GDP there is a decrease in imports. This is explained by decreased imports of MV\&P products reflecting improved competitiveness of the domestic MV\&P industry against imported MV\&P products.

The short-run increase in real wages reflects the strengthening of the labour market. However, consistent with our short-run wage hypothesis, the increase in real wages is initially quite small, certainly not sufficient to hold employment at its basecase forecast level against the positive influence of multi-factor productivity growth.

\subsection{Long-run macro results}

Between 2002 and 2006, Chart 4.1 shows continuation of the movements commenced in 2002. Reflecting the continued additions to productivity in the MV\&P industry, there are increasing positive deviations in GDP, aggregate employment, real investment, real consumption, the real exchange rate and the terms of trade, and increasing negative deviations in aggregate export and imports. Chart 4.1 also shows increasing positive deviations in aggregate capital arising from increased investment.

Beyond 2006, there are no further additional MV\&P productivity increases. Eventually wages rise sufficiently to force employment back to its basecase forecast level. With a fall in employment beyond 2006, the deviation in GDP also falls but remains positive. The deviation in GDP remains positive because the deviation in capital is positive and there is a permanent increase in economy-wide multi-factor productivity. The deviation in capital remains positive because real wage rates are permanently increased by improvements in the terms of trade and in productivity in the MV\&P industry. With higher real wages, the economy operates permanently with a higher $\mathrm{K} / \mathrm{L}$ ratio. Investment is permanently increased because the higher capital stock requires a higher level of replacement investment. Consumption is permanently increased because Australian households are made richer by the improvements in the terms of trade and in MV\&P productivity.

5 The increase in consumption is an indicator of the overall welfare effect of the shock under examination, 


\section{Increased attractiveness in Australia of domestic MV\&P products relative to imported MV\&P products (simulation 2)}

Results for this simulation are shown in Chart 5.1.

The macro effects of a preference twist towards domestic MV\&P products sufficient to raise MV\&P production by about 5 per cent are small and unfavourable. In 2006, the percentage deviation in aggregate employment is -0.006 . Negative deviations of a similar magnitude occur for real GDP, aggregate capital, aggregate consumption and the real wage rate. ${ }^{6}$

The unfavourable macro effects arise mainly from foreign ownership. With a preference twist towards domestic MV\&P products, there is increased profitability in the Australian MV\&P industry. ${ }^{7}$ Because the industry is largely foreign-owned, most of the increased profits accrue to foreigners. At the same time, increased MV\&P output, with consequent reductions in imports, strengthens the real exchange, thereby reducing profitability in Australia's export-oriented industries. On average these industries, especially agriculture and export-oriented manufacturing, have much lower foreign-ownership shares than MV\&P. Thus the shift in profitability towards the MV\&P industry and away from export-oriented industries reduces Australia's gross national product (that is, GDP minus net Australian-generated income accruing to foreigners). With a reduction in gross national product there is a reduction in consumption. To check this explanation, we ran a simulation in which the database was altered so that the foreign-ownership share of MV\&P was reduced to that of agriculture. In this simulation, the twist towards domestic MV\&P products generated small favourable macro effects.

The negative macro effects of foreign ownership are present in the simulation discussed in section 4 and in those to be discussed in sections 6 and 7. However these effects are small and are swamped in these simulations by the positive macro effects of productivity increases.

\section{Increased MV\&P exports (simulation 3)}

At the macro level the results in this simulation (Chart 6.1) are similar to those for the first simulation (Chart 4.1), except scaled down. As in the first simulation, the main macro driver in this simulation is an increase in MV\&P multi-factor productivity.

see Dixon and Rimmer (2002, pp. 102-103)

${ }^{6}$ The deviation lines for these variables are not shown in Chart 5.1. They are too close to the employment line to be distinguished.

7 Increased MV\&P profitability is dissipated in the very long run by increased capital in the industry. However, MV\&P profitability stays elevated throughout our simulation period, 2002 to 2011. 


\section{Chart 5.1. Selected macro variables: increased MV\&P attractiveness}

(\% deviations from basecase forecasts)

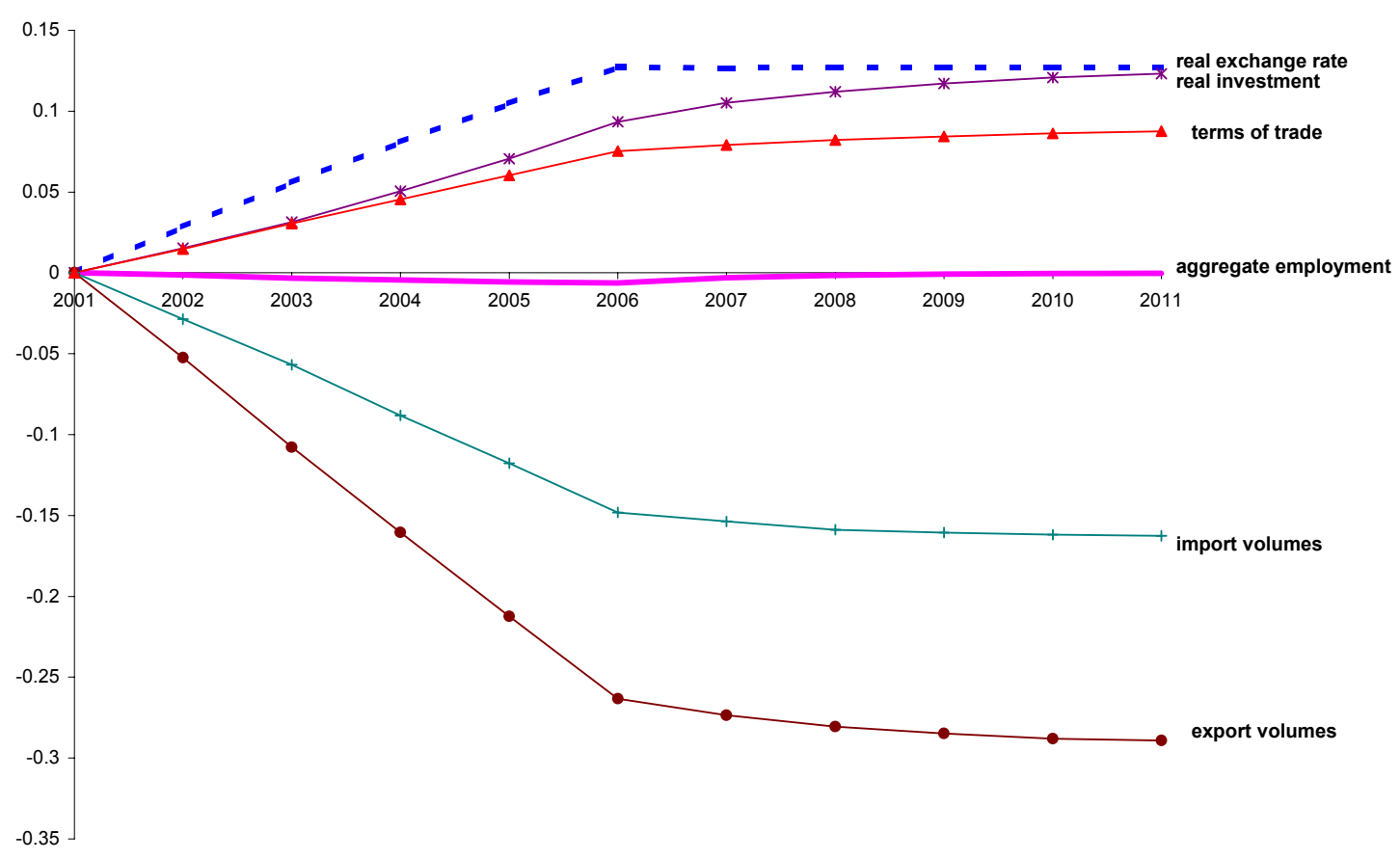

Chart 6.1. Selected macro variables: increased $M V \& P$ exports

(\% deviations from basecase forecasts)

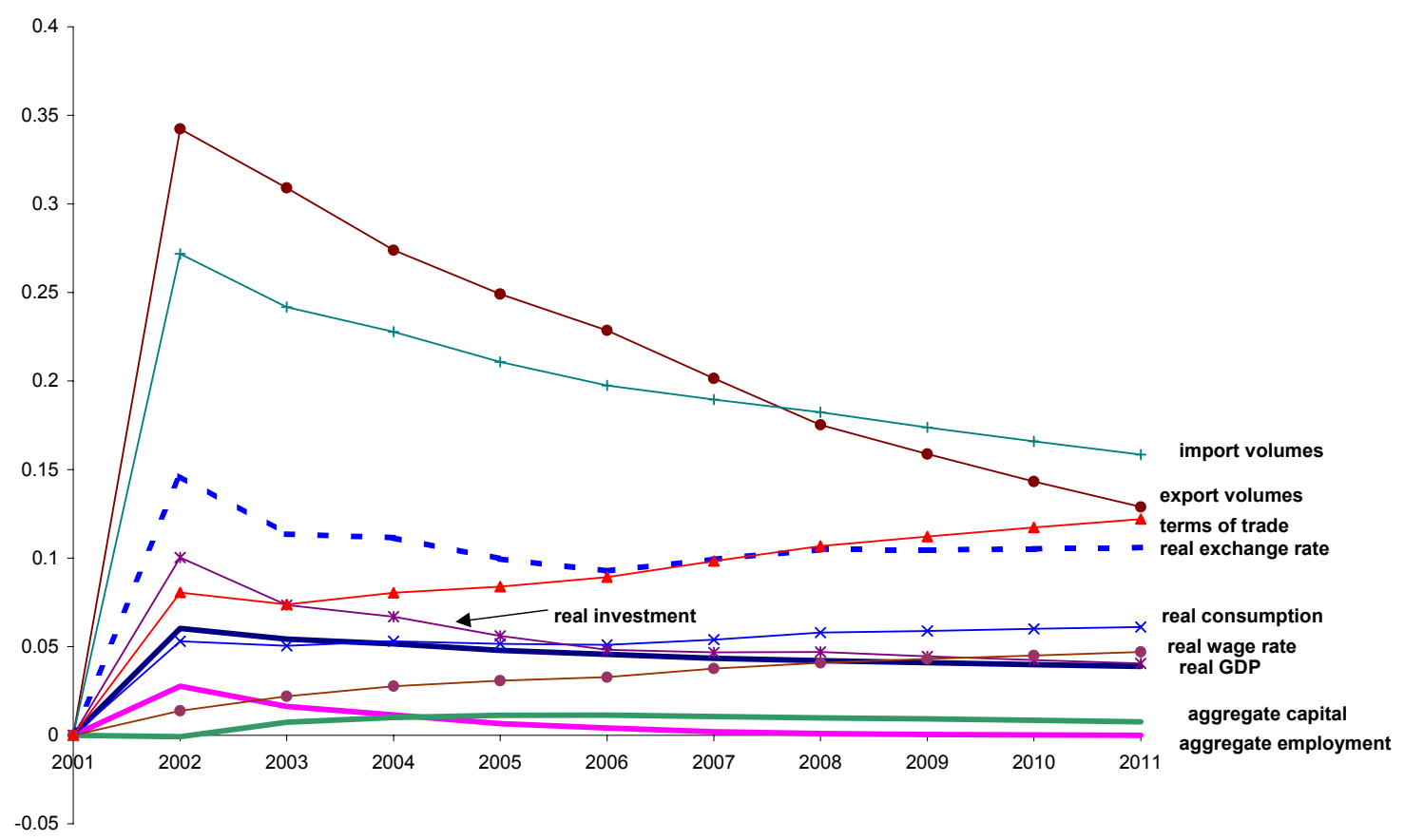


In the first simulation, the increase in MV\&P multi-factor productivity in 2006 reached 3.2 per cent. With inputs to the MV\&P industry being about 3 per cent of GDP, this translates into an economy-wide increase in multi-factor productivity in 2006 of 0.096 per cent. As explained in section 3, in the current simulation the increase in MV\&P multi-factor productivity is 1.15 per cent, translating into an economy-wide increase of 0.034 per cent. Thus the economywide multi-factor-productivity increase in the current simulation is about 30 per cent of that in the first simulation. For this reason, the current simulation shows percentage deviations in GDP and aggregate consumption in 2006 which are about 30 per cent as large as those in the first simulation (0.06 compared with 0.15 for GDP and 0.06 compared with 0.14 for consumption, Charts 6.1 and 4.1).

A point of contrast between the macro results in the first simulation and those in the current simulation concerns trade volumes. In Chart 4.1, export and import volumes contract whereas in Chart 6.1 they expand. In Chart 4.1, the contraction in aggregate imports reflects replacement of MV\&P imports by domestic products. In Chart 6.1 the expansion in aggregate exports reflects increased exports of MV\&P products. In both charts there is a strengthening of the real exchange rate. This explains reduced exports in Chart 4.1 and increased imports in Chart 6.1. In the first simulation the higher real exchange rate arose from reduced reliance on imported $\mathrm{MV} \& \mathrm{P}$ products combined with increased aggregate investment. In the current simulation, the higher real exchange rate arises from the increased ability to export MV\&P products combined with increased aggregate investment. In both simulations there is an improvement in the terms of trade associated with reduced exports of non-MV\&P products. In the current simulation we assume that Australia's increased allocation of exports in the world car market does not require a reduction in the foreign-currency price of these exports.

\section{A strongly growing MV\&P industry: combined shocks (simulation 4)}

\subsection{Macro results}

Chart 7.1 shows MONASH macro results with all the shocks from the previous simulations applied simultaneously. Detailed explanation is not required because the results in this chart are, to a close approximation, merely an addition of earlier results. For example, in Chart 7.1 the deviation in 2006 for the terms of trade is 0.208 per cent. This is approximately the sum of the deviations in Chart 4.1 (0.057), Chart 5.1 (0.075) and Chart $6.1(0.089)$. 


\section{Chart 7.1. Selected macro variables: combined MV\&P shocks (\% deviations from basecase forecasts)}

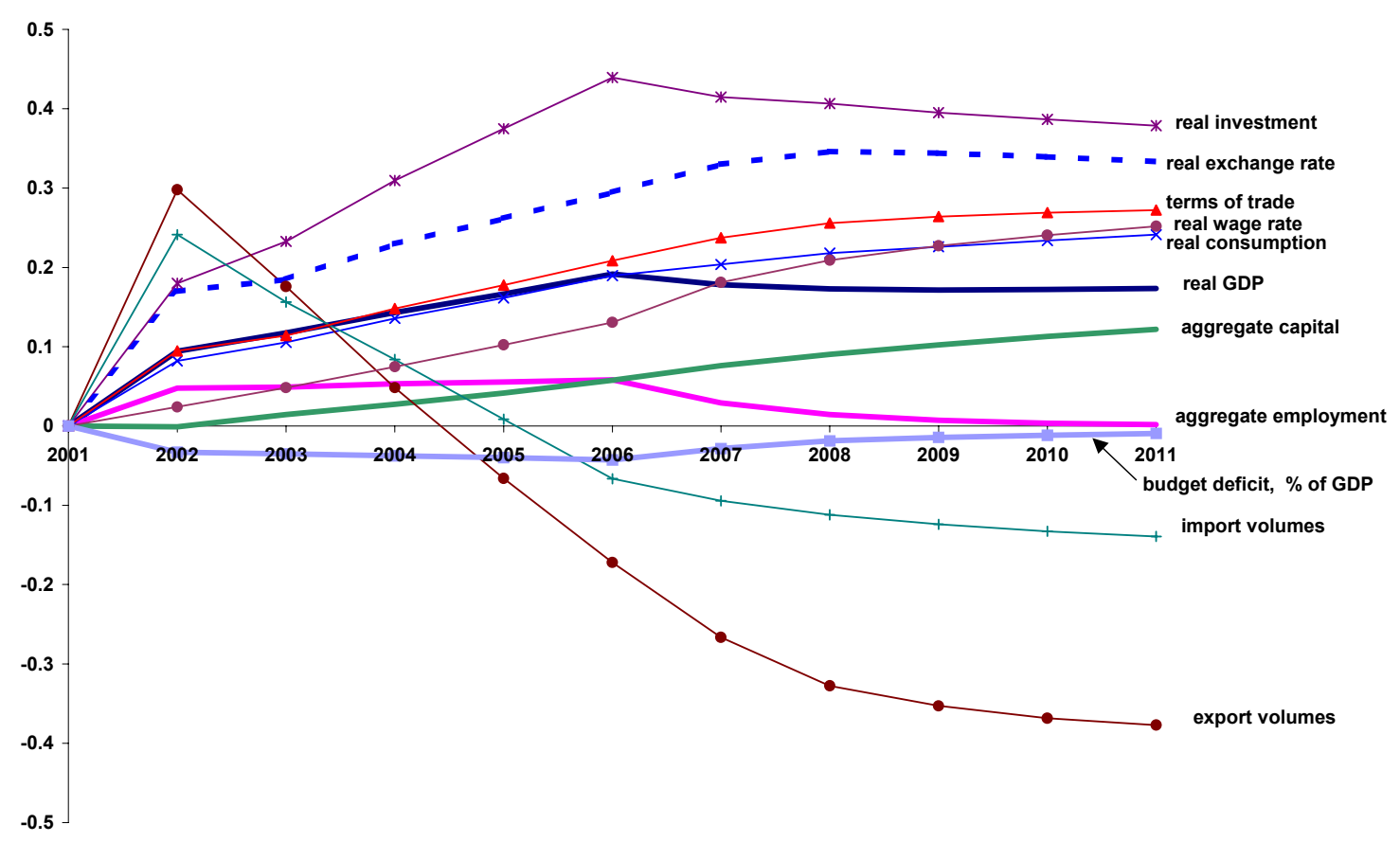

A new variable that we have included in Chart 7.1 is the public sector deficit as a percentage of GDP. The result for this variable in 2006, for example, means that with no changes in real public consumption or in tax and benefit rates, a faster growing MV\&P industry would reduce the public sector deficit by 0.043 per cent of GDP (about $\$ 300$ million). The government's improved budgetary position arises initially from reduced unemployment benefits reflecting increased employment and from increased tax revenue reflecting increased GDP. A slight offset is reduced tariff revenue associated with reduced imports of MV\&P products. Eventually in Chart 7.1, as employment returns to its forecast path, unemployment benefit payments increase and at the same time continuing growth in real wage rates leads to increases in the costs of public consumption. These two effects explain the return of the budget deficit towards its forecast path in the later part of the simulation.

\subsection{Results for the $M V \& P$ industry}

Results for MV\&P variables are shown for the combined shocks in Chart 7.2.

By construction, the combined shocks cause a deviation in MV\&P output of about 15 per cent in 2006 ( 20 per cent more output than in 2001 rather than 5 per cent more output). Extra productivity growth introduced in simulations 1 to 3 and extra attractiveness introduced in 


\section{Chart 7.2. MV\&P variables: combined MV\&P shocks \\ (\% deviations from basecase forecasts)}

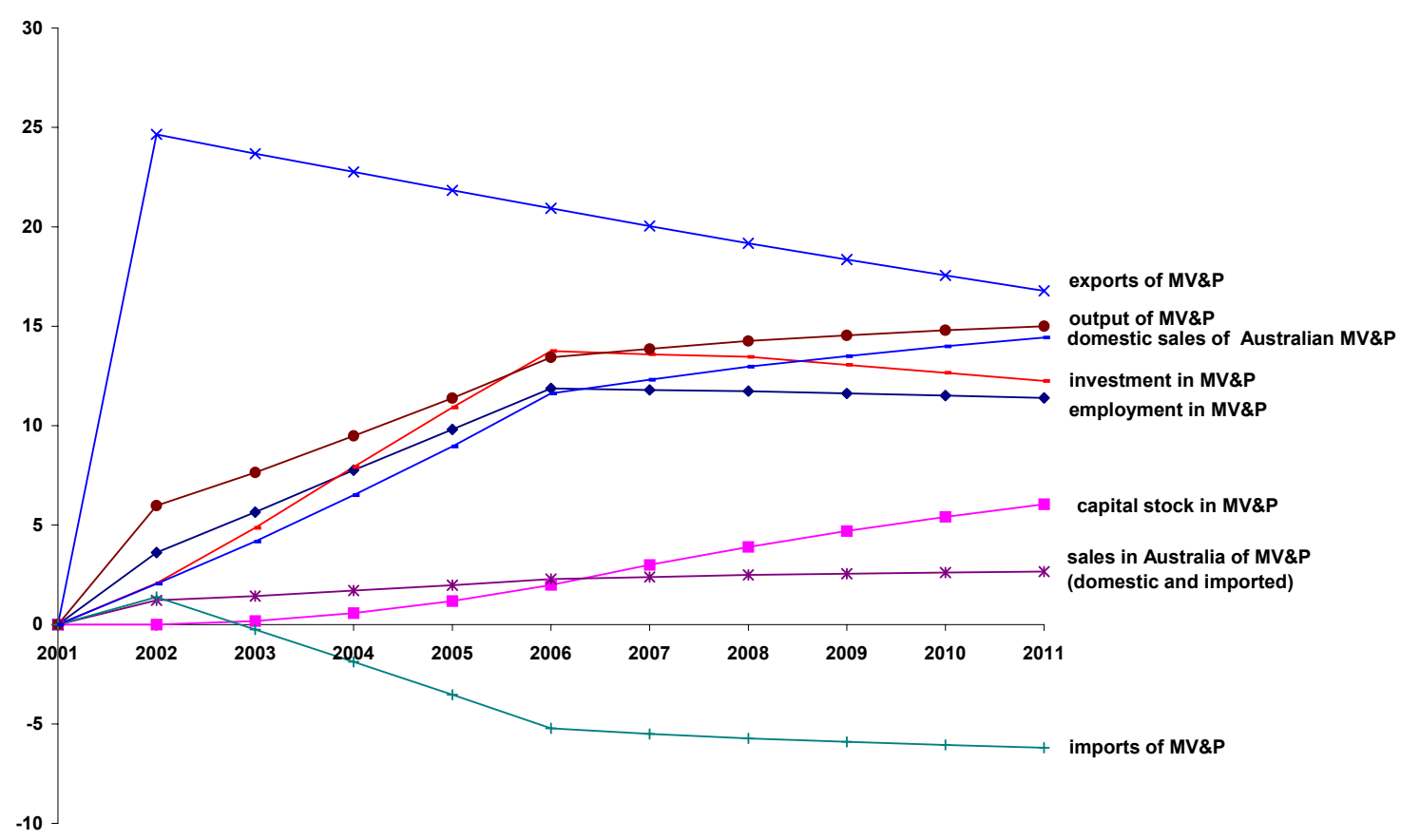

simulation 2 allow the MV\&P industry to increase its domestic sales by replacing imports of MV\&P products and to increase its profitability leading to increased investment and capital. The increase in output in the MV\&P industry is sufficient to generate an increase in MV\&P employment despite productivity growth. The deviation in MV\&P employment peaks in 2006 at 11.9 per cent, about 6,000 jobs.

Despite real appreciation, exports of MV\&P products show positive deviations in Chart 7.2. These result mainly from the shocks applied in simulation 3. Total sales (domestic and imported) of MV\&P products has positive deviations in Chart 7.2 for three reasons. First, there is an increase in the use of parts by the now expanded MV\&P industry. Second, there is an increase in investment usage of cars and trucks (reflecting increased aggregate investment, Chart 7.1). Third, there is an increase in household consumption of cars reflecting lower overall car prices resulting from higher local productivity and an appreciated real exchange rate (Chart 7.1).

\subsection{Results for other industries}

Chart 7.3 shows output deviations for those non-MV\&P industries that are most affected by fast growth in the MV\&P industry resulting from the combined shocks. Three of the main 


\section{Chart 7.3. Outputs of main winners and losers: combined MV\&P shocks (\% deviations from basecase forecasts)}

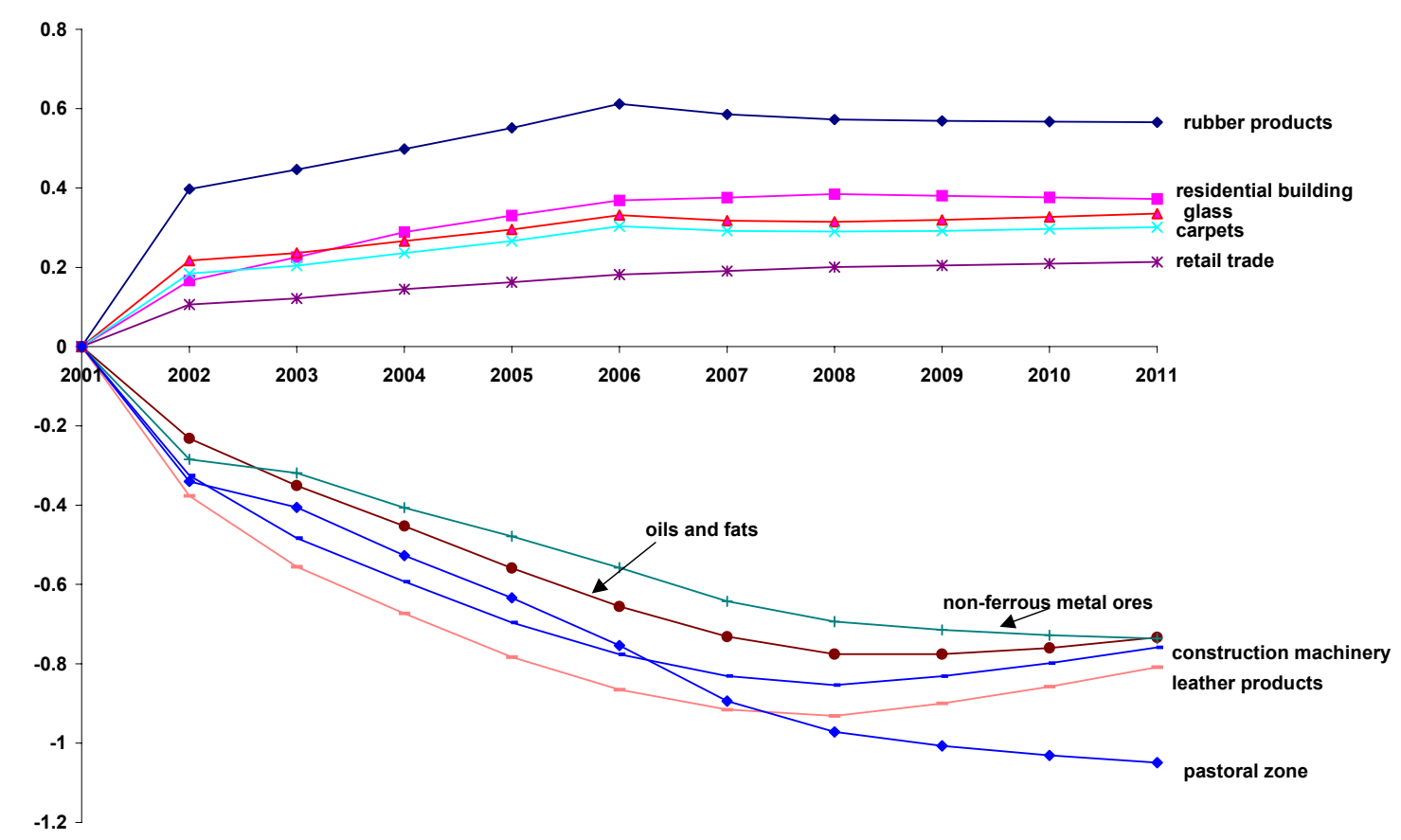

winning industries (rubber products, glass and carpets) have substantial sales to the MV\&P industry. The other main winning industries (residential building and retail trade) rely heavily on sales to consumers and investors. They gain from the expansions in aggregate consumption and investment (Chart 7.1). The main losers are export-oriented industries. These industries lose from a higher real exchange rate (Chart 7.1).

\section{Concluding remarks}

Industry representatives often imply that their industry's claim for special consideration (e.g. tariffs and subsidies) is enhanced by input-output studies showing high levels of direct employment and substantial multiplier-related employment in supplying industries. In our view, these studies are largely irrelevant. An industry does not make a contribution to the economy simply by using resources. It makes a contribution by improving the economy's use of resources. It can do this by taking up resources that would otherwise have been unemployed and by using resources more productively.

We have illustrated this idea by tracing out, with a dynamic CGE model, the contribution to the Australian economy that would be made by the MV\&P industry if its growth performance were to exceed a benchmark specified by a business-as-usual forecast. Among the alternative 
benchmarks that could be used are MV\&P performance indicators from other countries and performance indicators from other Australian industries. We prefer the business-as-usual benchmark. Because business-as-usual forecasts are made largely by extrapolating historical trends, such forecasts are likely to encapsulate background factors that are relevant to the performance of the Australian MV\&P industry.

Using the business-as-usual benchmark, we assessed the contribution that the MV\&P industry would make through increased productivity, through increased attractiveness of its products to Australian consumers and through increased exports. We showed (Chart 7.1) that extra MV\&P growth (3.6 per cent a year instead of 1 per cent) derived through these channels over the next five years would make the following contributions:

- a long-run increase in real GDP of 0.17 per cent or about $\$ 1.1$ billion;

- extra employment (from reductions in unemployment) in each of the 5 years up to 2006 of between 0.05 and 0.06 per cent or about 5 thousand jobs;

- a long-run increase in real household consumption of about 0.24 per cent or about $\$ 0.9$ billion;

- a long-run increase in the average real wage rate of about 0.25 per cent or about $\$ 100$ a year for a worker on average wages;

- a long-run improvement in the terms of trade of about 0.27 per cent; and

- a sustained improvement in the government's budgetary position raising the possibility of reduced tax rates.

These contributions are almost entirely associated with improved MV\&P productivity. As shown in section 5 (Chart 5.1), increased MV\&P growth without improvements in the use of resources does not make a contribution.

While CGE simulations can quantify an industry's potential contribution to the economy, they are not of direct relevance to policy discussions unless they are linked to policies. For the analysis presented here to become supporting evidence for a policy of assistance to the MV\&P industry, it would need to be supplemented by two types of information. First, it would be necessary to account for costs, including $R \& D$, associated with delivery of the MV\&P contribution. Second, it would be necessary to demonstrate that delivery of the contribution could not be achieved without assistance. 


\section{References}

Adams, P.D., B.R. Parmenter and J.M. Horridge (2000), “Analysis of Greenhouse Policy using MMRF-Green", paper presented at the third annual conference on Global Trade Analysis, Melbourne, pp. 19, available from the Centre of Policy Studies, Monash University, Clayton, Vic., 3800.

Dixon, P.B. and M.T. Rimmer (2002), Dynamic General Equilibrium Modelling for Forecasting and Policy: a Practical Guide and Documentation of MONASH, North-Holland Publishing Company, Amsterdam, pp. xiv +338.

Groenewold, N., A.J. Hagger and J.R. Madden (1987), "The Measurement of Industry Employment Contribution in an Input-Output Model”, Regional Studies, Vol. 21(3), pp. 255-63.

Groenewold, N., A.J. Hagger and J.R. Madden (1993), "Measuring industry importance: an Australian application", Annals of Regional Science, Vol. 27(2), pp. 175-182.

Jensen, R.C. and G.R. West (1986), Australian Regional Developments, 1. Input-Output for Practitioners: Theory and Applications, Australian Government Publishing Service, Canberra, pp. $\mathrm{x}+133$.

Naqvi, F. and M. Peter (1996), "A Multiregional, Multisectoral model of the Australian Economy with an Illustrative Application”, Australian Economic Papers, Vol. 35(66), pp. 94-113. 